\title{
Modulating Influence of Chemotactic Factor-Induced Cell Adhesiveness on Granulocyte Function
}

\author{
Jorg Fehr and Clemens Dahinden, Department of Medicine, Section of \\ Hematology CH 5, University of Zurich, CH-8091 Zurich, Switzerland
}

A B S T R A C T The importance of adhesion in regulating locomotion and accumulation of polymorphonuclear leukocytes (PMN) has remained vague. We found that the chemotaxis of human PMN resuspended in heat-inactivated plasma was maximal toward 1-10 $\mathrm{nM}$ $N$-formyl-met-leu-phe (f-Met-Leu-Phe), but fell below random motility toward $\geqslant 100 \mathrm{nM}$. This impressive decrease of motility was paralleled by increased cell adherence on Petri dishes being minimal at $1 \mathrm{nM}$ and maximal at $>10 \mathrm{nM}$ f-Met-Leu-Phe $(6 \pm 1$ and $37 \pm 2 \%$ [SE] adherent cells, respectively). Checked by phasecontrast microscopy, cells under stimulated adhesion lost the typical bipolar shape of moving PMN and became immobilized and highly flattened. PMN, preexposed to $250 \mathrm{nM}$ f-Met-Leu-Phe and tested after washing, retained increased adhesiveness and showed extremely low random and chemotactic motility. In contrast, preexposure to $1 \mathrm{nM}$ f-Met-Leu-Phe had no effect on chemotaxis. Supporting the concept that immobilizing hyperadhesiveness does not correspond to a general functional hyporesponsiveness of PMN, no depression of the initial ingestion rate was observed in the presence of $250 \mathrm{nM}$ f-Met-Leu-Phe. Moreover, a close correlation was found between the induction of PMN adhesiveness and the stimulation of the hexose monophosphate pathway activity as well as of lysomal enzyme release $(r \geqslant 0.98)$. Thus, "chemotactic deactivation" and "high-dose inhibition of chemotaxis" by $N$-formyl peptides is the consequence of increased cell adhesiveness. This phenomenon provides a mechanism for cell trapping at the inflammatory site. Conversely, if operative in circulating blood, e.g., in septicemia, it may impair PMN emigration to such sites.

This work was presented in part at a multidisciplinary session of the 35th Annual Meeting of the American Federation for Clinical Research, San Francisco, Calif., 1 May 1978 and was published in abstract form in 1978. Clin. Res. 26: 346A.

Received for publication 2 October 1978 and in revised form 29 January 1979.

\section{INTRODUCTION}

Local recruitment of polymorphonuclear leukocytes $(\mathrm{PMN})^{1}$ to inflammatory sites is essential to the host in its defense against invading microbial organisms. Although the knowledge of the direction-finding mechanisms of PMN has increased tremendously $(1,2)$, other mechanisms, in addition to directional migration (chemotaxis), must exist that are responsible for the ability of PMN to accumulate and to be retained at sites of infection $(1,3)$. The repeatedly made in vitro observation of an inhibition of cell orientation (4) or chemotaxis (5-8) with high concentrations of chemotactic factors have either gone unnoted or have found no reasonable explanation. Nevertheless, such findings are reminiscent of the situation at the inflammatory locus where leukocytes are trapped in a milieu with presumably high concentrations of chemotactic agents. Because, on the one hand, the importance of cell adhesion in regulating PMN locomotion is still not understood (9) and, on the other hand, excessive cellular adhesion could provide a potential mechanism as to how movement of PMN might be impeded and local cell trapping accomplished, we thought it worthwhile to study the interrelations between PMN locomotion and adhesiveness. The recent work, initiated by Schiffmann et al. (10), on synthetic $N$-formyl peptides made it possible to perform a comparative analysis of these two cellular characteristics in controlled concentrations of pure and highly potent chemoattractants.

\section{METHODS}

Preparation of leukocyte suspensions and plasma. Venous blood from healthy adult donors, collected in plastic syringes that contained preservative-free sodium heparin $(20 \mathrm{U} / \mathrm{ml}$ blood; Novo Industries, Copenhagen, Denmark) was mixed with $0.5 \mathrm{vol}$ of $6 \%(\mathrm{wt} / \mathrm{vol})$ dextran (Dextran 110, Fisons Ltd,

\footnotetext{
${ }^{1}$ Abbreviations used in this paper: HMP, hexose monophosphate pathway; HPF, high power field(s); MPO, myeloperoxidase; PMN, polymorphonuclear leukocytes.
} 
Loughborough, England) and allowed to sediment at room temperature. The leukocyte-rich supernate was centrifuged at $150 \mathrm{~g}$ for $8 \mathrm{~min}$ and, after lysis of residual erythrocytes with ice-cold hypotonic saline, the cells $(80-90 \%$ PMN, $10-20 \%$ mononuclear cells) were washed twice in Gey's solution (Gibco Diagnostics, Glasgow, Scotland) and, if not stated otherwise, suspended in autologous heat-inactivated plasma. Fresh autologous cell-free plasma was prepared simultaneously by collecting the blood in ice-cold plastic syringes. After transfer to precooled plastic tubes and centrifugation at $39,000 \mathrm{~g}$, the supernatant plasma was immediately decanted and anti-coagulated with $4 \mathrm{U}$ heparin $/ \mathrm{ml}$. Before it was used as cell suspension medium, the plasma was heatinactivated at $56^{\circ} \mathrm{C}$ for $30 \mathrm{~min}$ followed by removal of the precipitate by sedimentation at $39,000 \mathrm{~g}$ for $15 \mathrm{~min}$.

PMN chemotaxis. PMN random motility and directional migration was quantified by using the two-filter sandwich technique of Keller et al. (11), in modified Boyden chambers (Celloplex, Basel, Switzerland). 0.25-ml aliquots of leukocytes, suspended in heat-inactivated plasma (that contained $1 \times 10^{6}$ $\mathrm{PMN} / \mathrm{ml}$ ) were added to the upper compartment of the chamber, which was separated from the lower compartment by two micropore filters: an $8-\mu \mathrm{m}$ pore size filter (cellulose nitrate; Sartorius Inc., Göttingen, West Germany) was laid over a $0.45-\mu \mathrm{m}$ pore size filter (cellulose nitrate; Millipore Corp., Bedford, Mass.). The lower compartment of the chamber was filled either with autologous heat-inactivated plasma (random migration) or with the same medium to which the desired concentration of the chemoattractant had been added. The chambers were incubated for $60 \mathrm{~min}$ at $37^{\circ} \mathrm{C}$ and $100 \%$ humidity. The procedure outlined by Keller et al. (11) was followed exactly for fixation and staining. The PMN response in triplicate or quadruplicate chambers was quantified by counting the cells on the surface of both, the upper side of the cellimpermeable, and the lower side of the cell-permeable filter in 10 high power fields (HPF) corresponding to $1.5 \mathrm{~mm}^{2}$, with the aid of an eyepiece grid.

$P M N$ adherence. PMN adhesiveness was assessed as outlined (12). Briefly, duplicate 1-ml aliquots of leukocytes suspended in autologous heat-inactivated plasma (that contained $4 \times 10^{6} \mathrm{PMN} / \mathrm{ml}$ ), to which different concentrations of $N$-formyl peptides had been added, were incubated in $10 \times 35 \mathrm{~mm}$ Petri dishes (Corning Glass Works, Corning, N. Y.) for $40 \mathrm{~min}$ at $37^{\circ} \mathrm{C}$ and $100 \%$ humidity. Subsequently, the dishes were washed thoroughly in saline and dried at $4^{\circ} \mathrm{C}$. The amount of adherent cells was quantified by measuring their myeloperoxidase (MPO) content. Through knowledge of the number of cells placed on dishes and their initial MPO content, the absolute number of adherent cells remaining after washing could be determined. In some experiments, net release of lysozyme (13) and $\beta$-glucuronidase (14) during the incubation of the leukocytes on Petri dishes was also assayed with $8 \times 10^{6}$ $\mathrm{PMN} / \mathrm{ml}$. Under the conditions employed, release of MPO and lactic dehydrogenase (15) into the supernatant plasma was not observed.

Glucose oxidation by the hexose monophosphate pathway (HMP) of leukocytes in suspension. The activity of the HMP of leukocytes suspended in autologous heat-inactivated plasma to which different concentrations of $N$-formyl peptidases had been added, was determined by measuring the generation of ${ }^{14} \mathrm{CO}_{2}$ from $\left[1{ }^{14} \mathrm{C}\right]$ glucose $(16) .0 .6 \mu \mathrm{Ci}$ of $\left[1-^{14} \mathrm{C}\right]$ glucose $(57 \mathrm{mCi} /$ mmol; Amersham Corp., Buckinghamshire, England) was added to $1 \mathrm{ml}$ of cell suspension that contained $8 \times 10^{6} \mathrm{PMN}$, and the mixture was incubated in triplicate in $100 \times 20 \mathrm{~mm}$ plastic tubes with rubber caps fitted with cups (Kontes Co., Vineland, N. J.). To calculate the amount of glucose converted to $\mathrm{CO}_{2}$, the glucose concentration in heat-inactivated plasma was meas- ured by the glucose oxidase method (glucose analyzer, Beckman Instruments Inc., Fullerton, Calif.). After $30 \mathrm{~min}$ of incubation at $37^{\circ} \mathrm{C}$ in a shaking water bath, $0.2 \mathrm{ml}$ of Hyamine 10-X (Rohm \& Hass Co., Philadelphia, Pa.) was injected through the stopper into the cup and $0.2 \mathrm{ml}$ of $5 \mathrm{~N} \mathrm{H}_{2} \mathrm{SO}_{4}$ added to the cell suspension. After equilibration for $60 \mathrm{~min}$, the cups were placed in counting vials that contained $10 \mathrm{ml}$ of Instagel (Packard Instrument Co., Inc., Downers Grove, Ill.) and assayed in a liquid scintillation counter. The influence of $N$-formyl peptides on latex-stimulated HMP activity was also assessed (latex, Dow Corning Corp., Midland, Mich., mean particle diameter, $1.1 \mu \mathrm{m}$, final concentration of particles, $1 \%[\mathrm{vol} / \mathrm{vol}], 1-2 \times 10^{3}$ particles/PMN).

Phagocytic capacity of leukocytes. The rate of ingestion of leukocytes in the presence or absence of $N$-formyl peptides was quantified by the method of Stossel (17) with lipopolysaccharide-coated oil droplets. The procedure was followed as described (17) with the exception that the cell suspension medium consisted of heat-inactivated plasma and the droplets were prepared with diisodecyl phthalate (Polysciences Inc., Warrington, Pa.) instead of paraffin oil. ${ }^{2}$

Other compounds and reagents. The chemotactic peptides and analogues $N$-formyl-methionyl-leucyl-phenyl-alanine (fMet-Leu-Phe), $N$-formyl-methionyl-phenylalanine (f-Met-Phe), $N$-fomyl-phenylalanyl-methionine (f-Phe-Met), and methionylphenylalanine (Met-Phe) were obtained from Bachem AG, Bubendorf, Switzerland. Peptides were dissolved in a small volume of $0.15 \mathrm{~N} \mathrm{NaOH}$ and diluted in phosphate-buffered saline, with subsequent correction of the $\mathrm{pH}$ to 7.4 with $0.15 \mathrm{~N}$ $\mathrm{HCl}$. For in vitro experiments, the plasma dilution, through addition of buffered peptide solution, was $1 \%$ (vol/vol). Inulin (Sigma Chemical Co., St. Louis, Mo.) was sonicated in $0.9 \%$ saline, washed twice, and resuspended in phosphate-buffered saline, $\mathrm{pH} 7.4$, at $100 \mathrm{mg} / \mathrm{ml}$. The complement system of human plasma (prepared as outlined above) was activated by incubation for $30 \mathrm{~min}$ at $37^{\circ} \mathrm{C}$ with $5 \mathrm{mg}$ inulin $/ \mathrm{ml}$, followed by removal of inulin by means of sedimentation at $39,000 \mathrm{~g}$ for 15 min. Ficoll-Hypaque was obtained from Pharmacia Inc., Uppsala, Sweden. EDTA was the product of Sigma Chemical Co.

\section{RESULTS}

\section{In vitro adherence-inducing capacity of chemotactic peptides for human PMN}

Given the fact that chemotactic small molecular weight complement split products $(12,18)$, as well as the recently defined synthetic chemotactic peptides (19) produce an immediate but transient neutropenia when administered intravenously, an attempt was made to further substantiate our hypothesis that PMN margination in vivo and cell adhesiveness measured in vitro are closely associated phenomena (12). Therefore, the effect of different concentrations of f-Met-Leu-Phe and $\mathrm{f}-\mathrm{Met}-\mathrm{Ph}$, respectively, on PMN adhesiveness was assessed by means of our Petri dish assay, which quantitates adherent cells by measuring the retention of MPO activity on dishes after thorough washing. 95$100 \%$ pure autologous fresh plasma was chosen as the

\footnotetext{
${ }^{2}$ Stossel, T. P. 1976. Personal communication.
} 


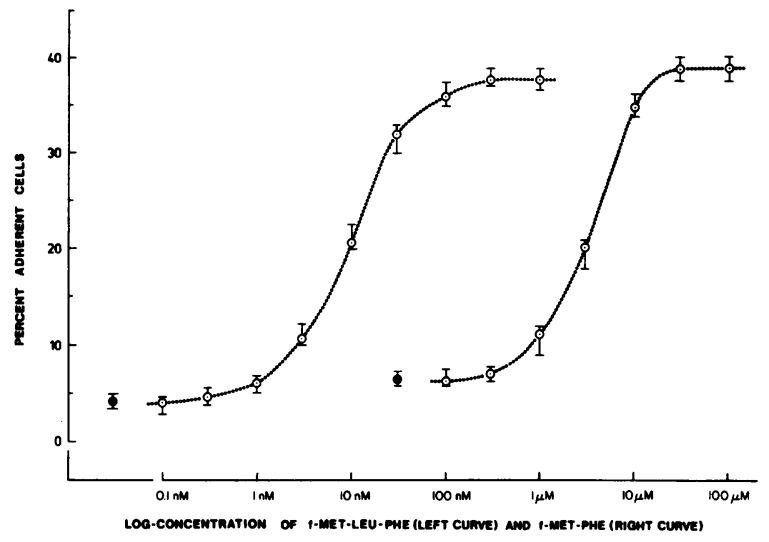

FIGURE 1 In vitro adherence-inducing capacity of f-MetLeu-Phe and f-Met-Phe for human PMN in autologous heatinactivated plasma. Adherent cells were quantitated by measuring their MPO content and expressed as percentage of the totally applied PMN. Symbols represent mean and range of four experiments performed with cells and plasma from a single donor. $\Phi$, percentage of adherent cells in heat-inactivated plasma without f-Met-Leu-Phe and f-Met-Phe, respectively.

suspension medium to represent the physiologic situation as closely as possible. On the other hand, knowledge of the influence of activated complement components on PMN adherence (12) meant that the plasma had to be heat-inactivated. As shown in Fig. 1, adherence was minimal and no different to the control in the presence of from 0.1 to $1.0 \mathrm{nM}$ f-Met-Leu-Phe, but began to increase at $3 \mathrm{~nm}$ and reached a maximum and plateau of nearly $40 \%$ adherent cells at concentrations higher than $100 \mathrm{nM}$. An identical sigmoidalshaped dose-response curve was obtained for adherence induction by the dipeptide f-Met-Phe, except that the profound change in this PMN surface characteristic occurred at a concentration roughly 1,000 times higher than that of the agent. The presence of $100 \mu \mathrm{M}$ of the positional isomer f-Phe-Met as well as of the nonformylated Met-Phe resulted in no measurable increase in PMN adhesiveness. Maximal PMN adherence for f-Met-Leu-Phe $(38 \pm 2 \%$ [SE] adherent cells) and f-MetPhe $(39 \pm 1 \%)$ was similar to the amount of cells that adhered when they were incubated in inulin-activated plasma $(35 \pm 4 \%, n=4)$. To exclude the influence of platelets and contaminating mononuclear cells on basal and stimulated adherence of PMN, experiments were also performed with pure PMN suspensions (96-99\% PMN, 1-4\% eosinophils) prepared by means of FicollHypaque density separation (20). Similar results, 8.8 $\pm 0.8 \%$ (SE) adherent cells in heat-inactivated plasma, and $39.4 \pm 2.2 \%$ adherent cells in the presence of 250 nM f-Met-Leu-Phe, were obtained with this PMN preparation $(n=6)$.

As far as morphologic changes of adherent PMN is concerned, there was a striking difference in the phase- contrast microscopic appearance of cells, which adhered in Sykes-Moore chambers under basal conditions (in heat-inactivated plasma) or the stimulated conditions (in the presence of appropriate concentrations of ditripeptides or inulin-activated plasma) (Fig. 2A and B). Cells incubated in heat-inactivated plasma revealed the typical bipolar shape of moving PMN (21) with veil-like, undulating hyaline lamellipodia and short, less flattened tails, and showed randomly directed locomotion with an approximate mean velocity of $6 \mu \mathrm{m} / \mathrm{min}$ (estimated by time-lapse cinematography with 20 frames/min). No gross difference was visible when a chemotactic concentration of f-Met-Leu-Phe ( $1 \mathrm{nM}$, cf. following paragraph) was added. In contrast, when PMN were incubated in the presence of maximal adhesion-promoting stimuli (250 nM f-Met-Leu-Phe, inulin-activated plasma), the cells lost their polarization, extended their hyaline lamellar processes over their entire circumference, and became highly flattened similar to spreaded monocytes (22). Although, these disk-like PMN were practically immobilized (checked by time-lapse cinematography), they showed continuous ruffling activity with extension and retraction of hyaline lamellae (Fig. 2C).

In ancillary studies with the rabbit model $(12,19)$, the dose of peptides needed to induce neutropenia exactly paralleled the adherence-promoting capacity of these agents. The correlation coefficient between neutropenia induction and adherence promotion was $-0.949(\mathrm{~N}$ $=8, P<0.001)$ for f-Met-Leu-Phe, and $-0.944(n=6$, $P<0.01$ ) for f-Met-Phe, respectively (regression analysis by the method of least squares).

Despite the fact that others have found that the addition of complement-activated serum (23) or synthetic chemotactic peptides (24) to PMN suspended in artificial media induced cell aggregation, it has been an absolutely consistent finding under conditions employed in our system that PMN did adhere in single-cell monolayers, without overlapping or formation of aggregates. Because it has been reported that PMN aggregation is transient and, therefore, a reversible change in PMN adhesiveness at low concentrations of peptides could have been missed, a time-course study at low ( $1 \mathrm{nM}$ ) and high $(1 \mu \mathrm{M})$ concentrations of f-Met-Leu-Phe was performed. As shown in Table I, no detectable increase in PMN adhesiveness was found at $1 \mathrm{nM}$ f-Met-LeuPhe, and, as viewed continuously by light microscopy, cells adhered in single cell monolayers. It should be noted explicitly that when PMN were suspended in artificial media like Hanks' balanced salt solution or Gey's solution, they revealed an unspecifically high adherence on Petri dishes $(44 \pm 3 \%$ [SD] adherent cells, $n=4$ ), which could not be modified significantly by addition of formylated peptides. Morphologically, such cells showed a high degree of flattening on the substratum. 

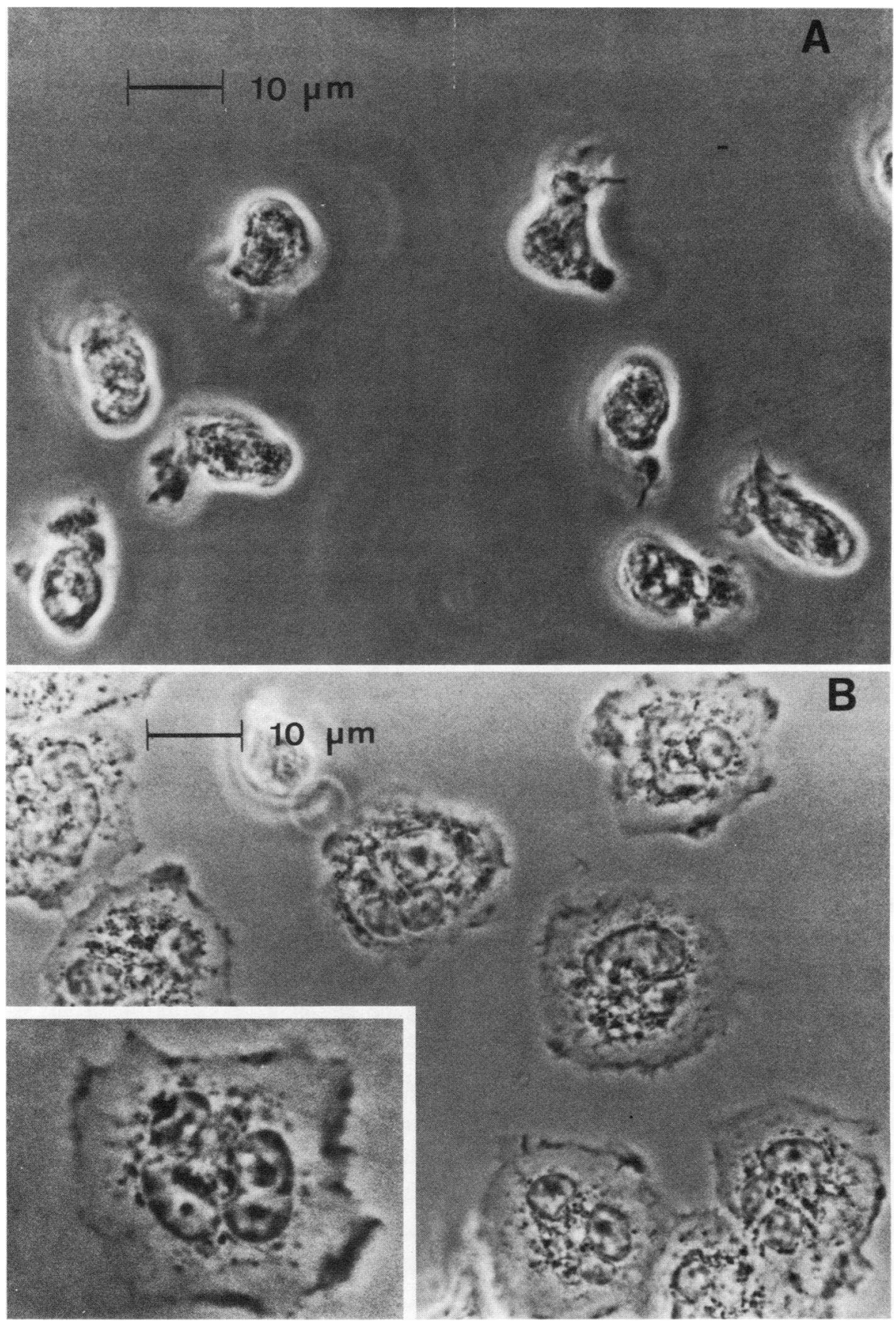

FIGURE 2 (A) PMN morphology under phase-contrast microscopy. Pure granulocyte suspensions were prepared by Ficoll-Hypaque separation and the cells were resuspended in autologous heat-inactivated plasma. Picture made after incubation at $37^{\circ} \mathrm{C}$ for $25 \mathrm{~min}$. (B) PMN morphology under the same conditions as in A, except that $250 \mathrm{nM}$ f-Met-Leu-Phe was present. (C) Extension and retraction of hyaline lamellae of PMN in the presence of $250 \mathrm{nM}$ f-Met-Leu-Phe as analyzed by time-lapse cinematography (20 frames/min). Outlines of two selected PMN were traced at 0,1 , and $2 \mathrm{~min}$. This type of motile activity continued over an observation period of $60 \mathrm{~min}$.
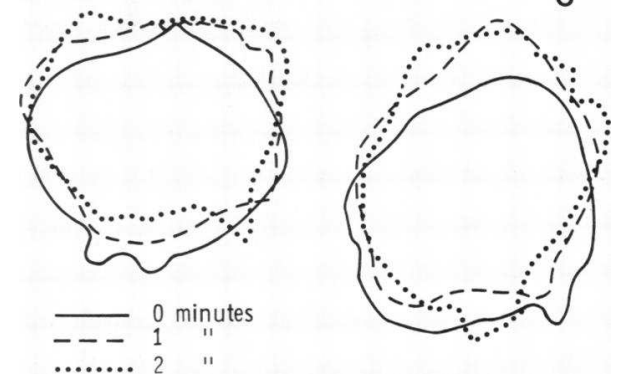
TABLE I

Time-Course of Adhesive Changes at Low (Chemotactic) and High Concentrations of $\mathrm{f}$-Met-Leu-Phe

\begin{tabular}{crrr}
\hline \multirow{2}{*}{$\begin{array}{c}\text { Duration of } \\
\text { incubation }\end{array}$} & \multicolumn{3}{c}{ Concentration of f-Met-Leu-Phe } \\
\cline { 2 - 4 } & \multicolumn{1}{c}{ None } & \multicolumn{1}{c}{$1 \mathrm{nM}$} & $1 \mu \mathrm{M}$ \\
\hline $\min$ & & & \\
10 & $3.5 \pm 0.4^{*}$ & $2.9 \pm 0.3 \ddagger$ & $32.9 \pm 1.9 \S$ \\
20 & $4.1 \pm 0.6$ & $3.0 \pm 0.1 \ddagger$ & $31.7 \pm 0.7 \S$ \\
40 & $10.2 \pm 0.9$ & $11.0 \pm 0.8 \ddagger$ & $36.0 \pm 1.5 \S$ \\
60 & $12.5 \pm 0.4$ & $11.7 \pm 0.3 \ddagger$ & $40.0 \pm 2.0 \S$
\end{tabular}

* Percentage of totally applied cells that adhered to Petri dishes (mean $\pm \mathrm{SD}$ of two experiments performed in triplicates).

$\ddagger P$ vs. control without f-Met-Leu-Phe $>0.05$ (Student's $t$ test). $\S P$ vs. control without f-Met-Leu-Phe $<0.001$.

\section{The dose dependency of the in vitro chemotactic activity of $\mathrm{N}$-formyl peptides and its relationship to PMN adhesiveness}

Because it is still an open and challenging question as to what extend the adhesiveness of PMN influences their motility, $\mathrm{N}$-formyl peptide-induced chemotaxis was analyzed with special reference to the adhesiveness-promoting potency of these agents. No attempt was made to define the lowest chemotactically active concentration of peptides. As shown in Fig. 3, the doseresponse study for the f-Met-Leu-Phe-induced chemotaxis resulted in maximal PMN migration towards 1 and $10 \mathrm{nM}$ tripeptide. Above this concentration, a striking inhibition of chemotaxis and even random motility be-

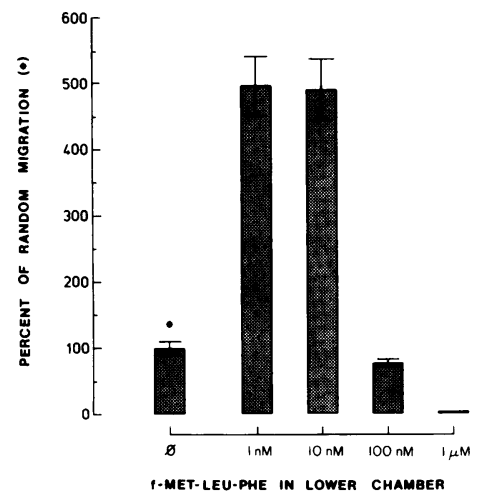

FIGURE 3 The concentration dependency of the chemotactic activity of f-Met-Leu-Phe for human PMN. Cells in the upper compartment were suspended in autologous heat-inactivated plasma and the same medium was present in the lower compartment to which different concentrations of the tripeptide had been added. Reference point for data representation is the random migration in heat-inactivated plasma that corresponded to $51 \pm 8(\mathrm{SE})$ cells/10 HPF. Data are derived from three experiments performed with triplicate chambers with cells and plasma from a single donor. Bars denote mean $\pm \mathrm{SE}$. came apparent: at $100 \mathrm{nM}$ tripeptide the amount of cells moving through the filter was already reduced to $79 \pm 4 \%$ (SE) of random migration $(P<0.005$, Student's $t$ test) and at over $1 \mu \mathrm{M}, \mathrm{PMN}$ were virtually trapped at or near the proximal surface of the upper filter. Again, the specificity of the phenomenon gained strong support through congruent findings obtained in analogous experiments with the less potent formylated dipeptide, f-Met-Phe (Fig. 4).

Under consideration of the concentration gradient of the peptides in the chemotactic chamber, the comparison of the chemotactic and adherence-promoting capacity of these agents tested clearly indicates that low concentrations of these peptides, which are already strongly chemotactic, do not induce a measurable change in PMN adhesiveness. On the other hand, when PMN encounter higher concentrations of these peptides, they become hyperadhesive leading to profoundly diminished directed and random migration in vitro. The correlation coefficient between inhibition of chemotaxis and augmentation of adhesiveness was $-0.980(n=6, P<0.001)$ for f-Met-Leu-Phe, and - $0.994(n=4, P<0.01)$ for $\mathrm{f}-$ Met-Phe, when the two functions were assayed with PMN from the same subject.

To provide further evidence that hyperadhesiveness is indeed a cellular characteristic that impedes the migratory response of PMN in a broader and somehow unspecific sense, experiments as compiled in Table II were performed. When PMN were made hyperadherent by adding appropriately high concentrations of f-Met-Leu-Phe to both sides of the filters in the Boyden chamber, these cells showed virtually abolished responsiveness to a gradient of complement-derived chemoattractants as produced by inulin-activated plasma. In contrast, such a directed migratory response was not impaired in the presence of a chemotactic ( 1 $\mathrm{nM}$ ) concentration of f-Met-Leu-Phe.

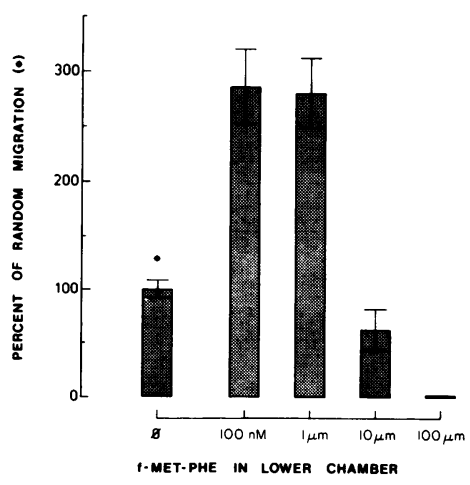

FIGURE 4 The concentration dependency of the chemotactic activity of f-Met-Phe for human PMN. Experimental conditions as outlined for Fig. 3. Random motility for this set of experiments was $108 \pm 9$ (SE) cells/10 HPF. 
TABLE II

Inhibition of Migration towards Complement-Derived Chemotactic Factor(s) by High Dose of Formylated Peptide

\begin{tabular}{llc}
\hline \multicolumn{2}{c}{ Chemotaxis in Boyden chambers } \\
\hline Upper compartment & \multicolumn{1}{c}{ Lower compartment } \\
\hline & & cells/10 HPF* \\
HIP & HIP & $485 \pm 93$ \\
HIP & c-fMLP & $2,153 \pm 148$ \\
HIP & $10 \%$ IAP & $2,591 \pm 208$ \\
a-fMLP & a-fMLP + 10\% IAP & $16 \pm 4$ \\
c-fMLP & c-fMLP + 10\% IAP & $2,040 \pm 172 \neq$
\end{tabular}

Abbreviations used in this table: HIP, autologous heatinactivated plasma; a-fMLP, $250 \mathrm{nM}$ f-Met-Leu-Phe; c-fMLP, $1 \mathrm{nM}$ f-Met-Leu-Phe; $10 \%$ IAP, $10 \%$ inulin-activated plasma in HIP ( $\mathrm{vol} / \mathrm{vol})$.

* Results represent the mean $\pm \mathrm{SE}$ of three experiments performed in triplicates with PMN obtained from a single donor. $\ddagger P$ vs. migration towards $10 \%$ IAP without $\mathrm{f}-\mathrm{Met}$-Leu-Phe $>0.05$ (Student's $t$ test).

\section{Chemotactic deactivation and its relationship to PMN adherence}

Although the phenomenon of the chemotactic deactivation, a term that describes the failure of leukocytes to migrate along a concentration gradient of a chemotactic stimulus as a result of a previous interaction with the active chemotactic factor $(25,26)$, is a well established fact in granulocyte function no data explaining this phenomenon, except the possible role of an activable esterase (25) have as yet been offered. With regard to the formylated peptides, the results presented in Fig. 5 indicate that the ability of these agents to deactivate PMN is strictly dependent on the concentration. PMN in heat-inactivated plasma were preincubated in a tumbling tube at $37^{\circ} \mathrm{C}$ for $15 \mathrm{~min}$ in the presence of a maximal chemotactic $(1 \mathrm{nM})$ or maximal adherence-promoting $(250 \mathrm{nM})$ concentration of f-MetLeu-Phe or, as a control, without adding any peptide. They were subsequently washed twice by centrifugation at $150 \mathrm{~g}$ for $7 \mathrm{~min}$ at $4^{\circ} \mathrm{C}$ in $40 \%$ heat-inactivated autologous plasma diluted with Gey's solution and resuspended in heat-inactivated plasma at appropriate concentrations to assess their random and chemotactic motility as well as their adhesiveness. The total washing procedure lasted 25-30 min and resulted in a dilution of the active agent by a factor of at least 5,000. The results of the migratory behavior in chemotactic chambers are shown in Fig. 5. In the control experiments (left) the pattern of results was identical to the data given in Fig. 3, with stimulated migration towards $1 \mathrm{nM}$ tripeptide and strongly inhibited motility towards 10 $\mathrm{nM}(P$ vs. random motility $<0.001$, Student's $t$ test $)$.

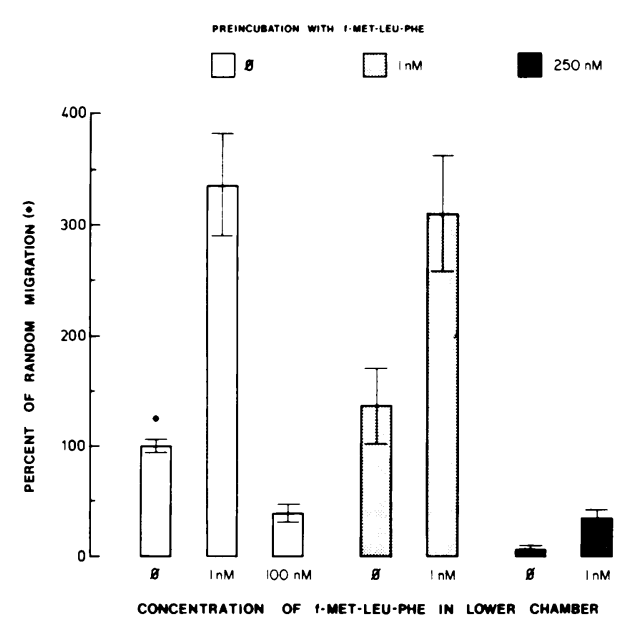

Figure 5 Ability of f-Met-Leu-Phe to irreversibly depress random motility and chemotactic response to the same stimulus (deactivation) after preincubation $\left(15 \mathrm{~min}, 37^{\circ} \mathrm{C}\right)$ at high concentrations of the tripeptide. Random motility for this experiment was $83 \pm 4(\mathrm{SE})$ cells/10 HPF. The experiment was repeated twice with $\mathrm{PMN}$ from different donors showing similar results. For further explanations, please see text.

When PMN were preincubated in a chemotactic concentration of the tripeptide ( $1 \mathrm{nM}$ ) (Fig. 5, center), subsequent random migration and chemotaxis after washing remained unchanged ( $P$ vs. control-incubated cells $>0.05)$. However, when PMN were preincubated with an adherence-promoting concentration $(250 \mathrm{nM})$ of f-Met-Leu-Phe, the subsequently measured random motility and chemotaxis towards the same stimulus was extremely low (Fig. 5 , right, $P$ vs. control random motility $<0.001$ ). Direct support for the conception that excessive surface affinity is indeed the basis for such motile cellular sluggishness was obtained by quantifying the Petri dish adhesiveness of identically treated PMN (three experiments). Preincubation without or in the presence of $1 \mathrm{nM}$ tripeptide kept adherence low $(6 \pm 1 \%$ [SE] and $8 \pm 2 \%$ adherent cells, respectively), whereas preexposure to $250 \mathrm{nM}$ f-Met-Leu-Phe resulted in retention of the increased adhesiveness despite the thorough washing procedure $(26 \pm 3 \%$ adherent cells; $P$ vs. adherence in heat-inactivated plasma without or with $1 \mathrm{nM}$ f-Met-Leu-Phe $<0.005$, Student's $t$ test).

\section{The influence of $N$-formyl peptides on basal and stimulated HMP activity, lysosomal enzyme release, and phagocytosis}

In the following series of experiments, the influence of different concentrations of $\mathrm{N}$-formyl peptides on some of the established systems, measuring in vitro PMN function, was analyzed:

Experiment 1. No increase in HMP activity was observed in our system when PMN were suspended in 
heat-inactivated plasma in the presence of a maximal chemotactic concentration of f-Met-Leu-Phe (Table III). However, when PMN were suspended in the presence of a hyperadhesion-inducing concentration of the same agent, they showed marked alteration in oxygen metabolism as measured through a consistent increase in the glucose oxidation via the HMP. When the adherence-promoting and the HMP-stimulating activities of different concentrations ( $1 \mathrm{nM}-1 \mu \mathrm{M})$ of f-Met-LeuPhe were correlated, a strikingly close linear relationship was obtained between these two PMN characteristics ( $r=0.98$; regression analysis by the method of least squares). Analogue results were obtained by using f-Met-Phe as the stimulus: the maximally chemotactic concentration of $1 \mu \mathrm{M}$ dipeptide induced no increment in the HMP activity $(119 \pm 11 \%$ [SE] of the control, $P$ $>0.05, n=4$ ), whereas 10 and $100 \mu \mathrm{M}$ f-Met-Phe increased this activity to $197 \pm 5$ and $209 \pm 12 \%$, respectively ( $P$ vs. control $<0.001, P$ between 10 and 100 $\mu \mathrm{M}>0.05)$. As a control, $100 \mu \mathrm{M}$ of the positional isomer f-Phe-Met induced no change in HMP activity $(103 \pm 7 \%, P>0.05 ; n=3)$.

Experiment 2. Lysosomal enzyme release on Petri dishes, quantitated by net liberation of lysozyme, exactly paralleled the results obtained for stimulation of adherence and HMP activity: no influence of a chemotactic concentration of f-Met-Leu-Phe on the one hand, a maximal and plateau-reaching activity at and over $250 \mathrm{nM}$ tripeptide on the other (Table III). Again, a strikingly close correlation was found between the ability of f-Met-Leu-Phe to promote PMN adherence and to induce lysozyme release on Petri dishes when these two cellular characteristics were measured simultaneously over a broad concentration range of the stimulating agent $(0.1 \mathrm{nM}-1 \mu \mathrm{M})$. The correlation co-

TABLE III

Influence of f-Met-Leu-Phe on HMP Activity and Lysosomal Enzyme Release

\begin{tabular}{|c|c|c|}
\hline $\begin{array}{l}\text { Concentration of } \\
\text { f-Met-Leu-Phe }\end{array}$ & $\begin{array}{c}\text { HMP activity } \\
37^{\circ} \mathrm{C}, 30 \mathrm{~min} \text {, in suspension } \\
(n=6)\end{array}$ & $\begin{array}{l}\text { Lysozyme release on } \\
\text { Petri dishes } \\
(n=5)\end{array}$ \\
\hline & $\%$ & $\mu g / m l$ \\
\hline none & $100^{*}$ & $1.05 \pm 0.10(\mathrm{SE})$ \\
\hline $1 \mathrm{nM}$ & $101 \pm 5$ & $0.86 \pm 0.14 \ddagger$ \\
\hline $10 \mathrm{nM}$ & $140 \pm 6 \S$ & $2.42 \pm 0.16^{\prime \prime}$ \\
\hline $250 \mathrm{nM}$ & $265 \pm 13^{\prime \prime}$ & $4.87 \pm 0.28^{\prime \prime}$ \\
\hline $1 \mu \mathrm{M}$ & $274 \pm 15$ & $4.95 \pm 0.31^{\pi}$ \\
\hline
\end{tabular}

The concentration of PMN in both test systems was $8 \times 10^{6} / \mathrm{ml}$.

* $6.3 \pm 0.4(\mathrm{SE}) \mathrm{nM}$ glucose $/ 10^{7} \mathrm{PMN}$ per $30 \mathrm{~min}$.

$\neq P$ vs. control without $\mathrm{f}-\mathrm{Met}$-Leu-Phe $>0.05$ (Student's $t$ test).

$\S P$ vs. control without $f-M e t-L e u-P h e<0.05$.

" $P$ vs. control without f-Met-Leu-Phe $<0.001$.

" $P$ vs. $250 \mathrm{nM}$ f-Met-Leu-Phe $>0.05$. efficient in five such experiments was $\geqslant 0.98$. An identical pattern of results, although with lower amounts of net enzyme liberation, was obtained when the release of $\beta$-glucuronidase was measured (results not shown).

Experiment 3. When the PMN phagocytic capacity was quantified by the sensitive "opsonized oil droplet method" (17), no difference was found in the initial $(5 \mathrm{~min})$ ingestion rate of $\mathrm{PMN}$ suspended in heat-inactivated plasma, either in the absence or in the presence of $250 \mathrm{nM}$ f-Met-Leu-Phe: $153 \pm 8(\mathrm{SE})$ and 150 $\pm 7 \mu$ g phthalate $/ 10^{7} \mathrm{PMN}$ per min, respectively $(n=4)$. That mere attachment of oil droplets without real internalization could have produced such a pseudoequality of the results was excluded in two ways: $(a)$ by addition of EDTA ( $5 \mathrm{mM}$ final concentration) after the 5 min incubation period at $37^{\circ} \mathrm{C}$, the results were not influenced significantly, a procedure which results in a complete detachment of PMN in our Petri dish assay and $(b)$ viewed by light microscopy, oil droplets were equally internalized in the presence or in the absence of f-Met-Leu-Phe. In addition, when the phagocytosisinduced "respiratory burst" was estimated by glucose oxidation via the HMP in the presence of an optimal concentration (27) of latex particles, the values obtained after preincubation $\left(5 \mathrm{~min}, 37^{\circ} \mathrm{C}\right)$ of $\mathrm{PMN}$ with $250 \mu \mathrm{M}$ f-Met-Leu-Phe were somewhat higher, but a statistically significant difference was not attained: $329 \pm 30$ $(\mathrm{SE})$ vs. $382 \pm 40 \mathrm{nM}$ glucose $/ 10^{7} \mathrm{PMN}$ per $30 \mathrm{~min}(P$ $>0.05$, Student's $t$ test; $n=5$ ).

\section{DISCUSSION}

Mainly for theoretical reasons, it has become widely accepted that attachment of cells to the substratum is a prerequisite for migration to occur (28-30). Nevertheless, on more practical grounds, the importance of adhesion in regulating locomotion and accumulation of leukocytes has remained vague (9). With the synthetic chemotactic $N$-formyl peptides, our study demonstrates an impressive inverse relationship between PMN motility and adhesiveness. That this phenomenon is not restricted to effects of $N$-formyl peptides, but has much broader implications for the regulation of PMN locomotion, is suggested for three reasons: (a) A natural low molecular weight chemoattractant from Escherichia coli supernate interacts with the same receptor site as the synthetic peptides (21). (b) A similar high-dose inhibition of chemotaxis has recently been found with purified C5a (8), an attractant with a different receptor site $(7,31)$. (c) PMN made hyperadhesive by f-MetLeu-Phe, also showed abolished migration towards complement-derived chemoattractants (Table II). With regard to the more than 10-yr-old term of "chemotactic deactivation" (25), our study provides evidence that increased cell adhesiveness plays a causative role 
in this phenomenon. Based on our results, it should be emphasized that this form of "deactivation", in a strict sense, does not correspond to an impairment in the direction finding mechanism. Rather, what can be observed is a more general depressing effect on the basic migratory machinery of the PMN apparent in a persistent, extremely low random motility, a finding which has recently been confirmed with complement-activated serum as preincubation medium (32). Our observations do not exclude the existence of other mechanisms of deactivation, because, besides several studies reporting deactivation with relatively high doses of chemotactic factors $(25,32,33)$, low-dose chemotactic deactivation has been found for other PMN (26) and eosinophil $(34,35)$ chemoattractants.

In analyzing the effect of different concentrations of $\mathrm{N}$-formyl peptides on three established in vitro assay systems, which are thought to measure most essential PMN functions, support was gained for the concept that PMN hyperadhesiveness and chemotactic desensitation do not correspond with a general functional hyporesponsiveness of these cells. The most important indication that hyperadherence-inducing concentrations of $N$-formyl peptides are not toxic to PMN is the fact that no depression of the initial ingestion rate was found in the presence of an appropriate concentration of f-Met-Leu-Phe. From parallelism between stimulation of the HMP activity and release of lysosomal enzymes on the one hand and adherence induction on the other, combined with the as yet still unexplained observations that many of the peptide-induced PMN alterations have their dose-response maximum clearly above their optimal chemotactic concentration $(6,36-38)$, the conclusion can be drawn that these stimulatory events are chiefly related to the termination of locomotion (39). Thus, the in respect of locomotion deactivated PMN show alterations that reflect a stimulated, highly reactive cellular condition.

Bearing in mind that simple conclusions from analogy cannot be made, the present study may nevertheless have considerable implications with reference to the living organism. PMN hyperadhesiveness may indeed be an important prerequisite in the mechanism of local cell trapping at the inflammatory site. Conversely, if these mechanisms are operating in circulating blood, e.g., in septicemia, granulocyte emigration to the inflammed focus may be impaired and bacterial dissemination facilitated. Furthermore, an analysis of the role of PMN adhesiveness in situations where in vivo chemotactic deactivation has been inferred as the cause of a chemotactic hyporesponsiveness $(26,35,40)$ or in secondary granulocytopathies as exemplified by a recent case report of an juvenile peridontitis showing extremely spreaded PMN in vitro (41), may help to extend the clinical significance of these PMN surface characteristic.
The fundamental question of whether the immobilizing adhesion is accomplished either directly (active rearrangement of contractile proteins [30] and formation of podosomes [42]) or more indirectly through membrane alterations mediated by released lysosomal enzymes (43), remains unsolved.

\section{ACKNOWLEDGMENTS}

The authors are grateful to Mrs. Elisabeth Bächler and Ms. Marianne Brauen for their excellent technical assistance and thank Dr. Gisela Hämmerli for her expert guidance in studies with phase-contrast microscopy and time-lapse cinematography.

\section{REFERENCES}

1. Becker, E. L. 1977. Stimulated neutrophil locomotion. Chemokinesis and chemotaxis. Arch. Pathol. Lab. Med. 101: 509-513.

2. Zigmond, S. H. 1978. Chemotaxis by polymorphonuclear leukocytes. J. Cell. Biol. 77: 269-287.

3. Keller, H. U., J. Wissler, M. W. Hess, and H. Cottier. 1977. Chemokinesis and chemotaxis of phagocytes. In Movement, Metabolism and Bactericidal Mechanisms of Phagocyte. F. Rossi, P. Patriarca, and D. Romeo, editors. Piccin Medical Books, Pavia. 15-19.

4. Zigmond, S. H. 1977. Ability of polymorphonuclear leukocytes to orient in gradients of chemotactic factors. J. Cell Biol. 75: 606-616.

5. Becker, E. L. 1972. The relationship of the chemotactic behaviour of the complement-derived factors, C3a, C5a $\mathrm{C} \overline{567}$, and a bacterial chemotactic factor to their ability to activate the proesterase 1 of rabbit polymorphonuclear leukocytes. J. Exp. Med. 135: 376-387.

6. Showell, H. J., R. J. Freer, S. H. Zigmond, E. Schiffmann, S. Aswanikumar, B. Corcoran, and E. L. Becker. 1976. The structure-activity relations of synthetic peptides as chemotactic factors and inducers of lysosomal enzyme secretion for neutrophils. J. Exp. Med. 143: 1154-1169.

7. Williams, L. T., R. Synderman, M. C. Pike, and R. J. Lefkowitz. 1977. Specific receptor sites for chemotactic peptides on human polymorphonuclear leukocytes. Proc. Natl. Acad. Sci. U. S. A. 74: 1204-1208.

8. Fernandez, H. N., P. M. Henson, A. Otani, and T. E. Hugli. 1978. Chemotactic response to human C3a and C5a anaphylatoxins. I. Evaluation of C3a and C5a leukotaxis in vitro and under simulated in vivo conditions. J. Immunol. 120: $109-115$.

9. Wilkinson, P. C., and R. B. Allan. 1978. Assay systems for measuring leukocyte locomotion: an overview. In Leukocyte Chemotaxis: Methods, Physiology, and Clinical Implications. J. I. Gallin, and P. G. Quie, editors. Raven Press, New York. 1-24.

10. Schiffmann, E., B. A. Corcoran, and S. M. Wahl. 1975. $\mathrm{N}$-formylmethionyl peptides as chemoattractants for leukocytes. Proc. Natl. Acad. Sci. U. S. A. 72: 1059-1062.

11. Keller, H. U., H. Gerber, M. W. Hess, and H. Cottier. 1976. Studies on the regulation of the neutrophil chemotactic response using a rapid and reliable method for measuring random migration and chemotaxis of neutrophil granulocytes. Agents Actions. 6: 326-339.

12. Fehr, J., and H. S. Jacob. 1977. In vitro granulocyte adherence and in vivo margination: two associated complement-dependent functions. Studies based on the acute neutropenia of filtration leukophoresis. J. Exp. Med. 146: 641-652. 
13. Worthington Enzyme Manual. 1972. Worthington Biochemical Corp., Freehold, N. J. 100-101.

14. Bittinger, G., R. Hirschhorn, S. D. Douglas, and G. Weissmann. 1968. Studies on lysosomes. XI. Characterization of a hydrolase-rich fraction from human lymphocytes. $J$. Cell Biol. 37: 394-411.

15. Wroblewski, F., and J. S. LaDue. 1955. Lactic dehydrogenase activity in blood. Proc. Soc. Exp. Biol. Med. 90: $210-213$.

16. Boxer, L. S., and T. P. Stossel. 1974. Effects of antihuman neutrophil antibodies in vitro. Quantitative studies. J. Clin. Invest. 53: 1534-1545.

17. Stossel, T. P., and M. Taylor. 1976. Phagocytosis. In Manual of Clinical Immunology. N. R. Rose, and $\mathrm{H}$. Friedman, editors. American Society of Microbiology, Washington, D. C. 148-154.

18. Craddock, P. R., J. Fehr, A. P. Dalmasso, K. L. Brigham, and H. S. Jacob. 1977. Hemodialysis neutropenia. Pulmonary vascular leukostasis resulting from complement activation by dialyzer cellophane membranes. $J$. Clin. Invest. 59: 879-888.

19. O'Flaherty, J. T., H. J. Showell, and P. A. Ward. 1977. Neutropenia induced by systemic infusion of chemotactic factors. J. Immunol. 118: 1586-1589.

20. Boyum, A. 1968. Isolation of mononuclear cells and granulocytes from human blood: isolation of mononuclear cells by one centrifugation, and of granulocytes by combining centrifugation and sedimentation at $1 \mathrm{~g}$. Scand. J. Clin. Lab. Invest. 21 (Suppl. 97): 77-89.

21. Armstrong, P. B., and J. M. Lackie. 1975. Studies on intracellular invasion in vitro using rabbit peritoneal neutrophil granulocytes (PMNS). I. Role of contact inhibition of locomotion. J. Cell Biol. 65: 439-462.

22. Rabinovitch, M. 1975. Macrophage spreading. In Mononuclear Phagocytes in Immunity, Infection, and Pathology. R. Van Furth, editor. Blackwell Scientific Publications Ltd., Oxford. 369-385.

23. Craddock, P. R., D. Hammerschmidt, J. G. White, A. P Dalmasso, and H. S. Jacob. 1977. Complement(C5a)induced granulocyte aggregation in vitro. A possible mechanism of complement-mediated leukostasis and leukopenia. J. Clin. Invest. 60: 260-264.

24. O'Flaherty, J. T., D. L. Kreutzer, and P. A. Ward. 1977. Neutrophil aggregation and swelling induced by chemotactic agents. J. Immunol. 119: 232-239.

25. Ward, P. A., and E. L. Becker. 1968. The deactivation of rabbit neutrophils by chemotactic factor and the nature of the activable esterase. J. Exp. Med. 127: 693-709.

26. Wasserman, S. I., N. A. Soter, D. M. Center, and K. F. Austen. 1977. Cold urticaria. Recognition and characterization of a neutrophil chemotactic factor which appears in serum during experimental cold challenge.J. Clin. Invest. 60: $189-196$.

27. Weening, R. S., D. Roos, and J. A. Loos. 1974. Oxygen consumption of phagocytizing cells in human leukocyte and granulocyte preparations: a comparative study. J. Lab. Clin. Med. 83: 570-576.

28. Weiss, L. 1971. Biophysical aspects of initial cell interactions with solid surfaces. Fed. Proc. 30: 1649- 1657.

29. Keller, H. U., M. W. Hess, and H. Cottier. 1975.
Physiology of chemotaxis and random motility. Semin. Hematol. 12: 47-57.

30. Stossel, T. P. 1978. The mechanism of leukocyte locomotion. In Leukocyte Chemotaxis: Methods, Physiology, and Clinical Implications. J. I. Gallin and P. G. Quie, editors. Raven Press, New York. 143-160.

31. Aswanikumar, S., B. Corcoran, E. Schiffmann, A. R. Day, R. J. Freer, H. J. Showell, E. L. Becker, and C. B. Pert. 1977. Demonstration of a receptor on rabbit neutrophils for chemotactic peptides. Biochem. Biophys. Res. Commun. 74: 810-817.

32. Nelson, R. D., R. T. McCormack, V. D. Fiegel, R. L. Simmons, and P. G. Quie. 1978. Evidence for two components of chemotactic deactivation (CD) of human polymorphonuclear neutrophils (PMN). Fed. Proc. 37: 935. (Abstr.)

33. Issekutz, A. C., and W. D. Biggar. 1977. Influence of serumderived chemotactic factors and bacterial products on human neutrophil chemotaxis. Infect. Immun. 15: 212-220.

34. Wasserman, S. I., D. Whitmer, E. J. Goetzl, and K. F. Austen. 1975. Chemotactic deactivation of human eosinophils by the eosinophilic factor of anaphylaxis. Proc. Soc. Exp. Biol. Med. 148: 301-306.

35. Goetzl, E. J., A. H. Tashjian, R. H. Rubin, and K. F. Austen. 1978. Production of a low molecular weight eosinophil polymorphonuclear leukocyte chemotactic factor by anaplastic squamous cell carcinomas of human lung. $J$. Clin. Invest. 61: 770-780.

36. Becker, E. L. 1976. Some interrelations of neutrophil chemotaxis, lysosomal enzyme secretion, and phagocytosis as revealed by synthetic peptides. Am. J. Pathol. 85: 385-394.

37. Hatch, G. E., D. E. Gardner, and D. D. Menzel. 1978. Chemiluminescence of phagocytic cells caused by $N$-formyl-methionyl peptides. J. Exp. Med. 147: 182-195.

38. Gallin, E. K., and J. E. Gallin. 1977. Interaction of chemotactic factors with human macrophages. Induction of transmembrane potential changes. J. Cell Biol. 75: 277-289.

39. Gallin, J. I., E. K. Gallin, H. L. Malech, and E. B. Cramer. 1978. Structural and ionic events during leukocyte chemotaxis. In Leukocyte Chemotaxis: Methods, Physiology, and Clinical Implications. J. I. Gallin, and P. G. Quie, editors. Raven Press, New York. 123-141.

40. Bowers, T. K., P. R. Craddock, and H. S. Jacob. 1977. Acquired granulocyte abnormality during drug allergic reactions: possible role of complement activation. Blood. 49: 3-8.

41. Shurin, S., E. Sweeney, S. Socransky, and T. P. Stossel. 1978. Systemic neutrophil (PMN) dysfunction caused by a peridontal pathogen. Clin. Res. 26: 406A. (Abstr.)

42. Hartwig, J. H., W. A. Davies, and T. P. Stossel. 1977. Evidence for contractile protein translocation in macrophage spreading, phagocytosis, and phagolysosome formation. J. Cell Biol. 75: 956-967.

43. Gallin, J. I., D. G. Wright, and E. Schiffmann. 1978. Role of secretory events in modulating human neutrophil chemotaxis. J. Clin. Invest. 62: 1364-1374. 